\title{
Serum Apelin Levels in Psoriasis: A Case-controlled Prospective Study
}

\author{
(1) Tuğba Kevser Üstünbaș Uzunçakmak¹, (1) Hayriye Erman², (1) Ayșe Serap Karadağ ${ }^{1}$, (1) Necmettin Akdeniz
}

1/stanbul Medeniyet University Faculty of Medicine, Department of Dermatology, Istanbul, Turkey

2Istanbul Medeniyet University Faculty of Medicine, Department of Biochemistry, Istanbul, Turkey

\section{ABSTRACT}

Background: Psoriasis is a chronic, inflammatory skin disease which is closely associated with obesity, cardiovascular diseases (CVD), diabetes and metabolic syndrome. Adipokines are a large of group bioactive substances secreted from adipose tissue which are involved in various metabolic diseases including psoriasis. Apelin is a very new described adipokine in this group. We aimed to evaluate the difference of serum apelin levels in patients with psoriasis vulgaris and healthy volunteers.

Materials and Methods: Fourty volunteers and 37 patients with psoriasis vulgaris were recruited in this study. Healthy adults, with no known diagnosis of cancer, CVD, diabetes mellitus, kidney failure and hematologic disorders were included in control group. Psoriasis was diagnosed according to physical and histopathological examination. Venous blood was collected into serum separate or tubes with clot activator. Biochemical analyses including fasting glucose, homeostatic model assessment-insulin resistance (HOMA-IR), insulin, erythrocyte sedimentation rate, C-reactive protein (CRP), hemoglobin A1c (HbA1c), total cholesterol, low density lipoprotein (LDL), high density lipoprotein (HDL), triglycerides (TG) were done. Serum fasting apelin concentration was measured with the ELISA assay.

Results: The mean ages of participants of psoriasis were 43 years, and 23 male, 14 female. The mean ages of a control group were 41 years, 17 male and 23 female. There were no statistically significant differences between patient and control groups according to serum levels of total cholesterol, LDL, HDL, TG, glucose, HbA1c, CRP, and erythrocyte. The mean value of serum apelin concentration in control and patient groups were 0.13 and $0.10 \mathrm{pg} / \mathrm{mL}$, respectively, and there were statistically significant differences. Serum apelin concentration was only correlated with age. There was no correlation between serum apelin concentrations and other biochemical parameters and HOMA-IR values.

Conclusion: In our study, we found a statistically significant difference between two groups according to serum apelin concentrations.

Keywords: Adipokine, Apelin, Inflammation, Psoriasis

\section{Introduction}

Psoriasis is a chronic, T cell mediated, inflammatory skin disorder which is affecting 2-3\% of the population [1]. In the long term follow up psoriatic patients were shown to have an increased prevalence of different comorbidities including obesity, cardiovascular disease (CVD), inflammatory bowel disease, psychiatric disorders, metabolic syndrome and its components $[1,2,3,4,5]$. The mechanism between psoriatic skin inflammation and systemic comorbidities is still unknown, but recently psoriasis is accepted as a part of the systemic inflammation named as "psoriatic march" more than being only a single organ disease [2].

The association of psoriasis with metabolic syndrome and obesity has been reported in several studies in the literature [6]. The exact mechanism is still unknown, but long lasting chronic inflammation 
and inflammatory mediators are considered as the initiators of the development of metabolic syndrome. Moreover hypertension, dyslipidemia, insulin resistance and obesity are reported to be independently related to psoriasis other than as components of metabolic syndrome [4]. Adipose tissue is not only protecting the internal organs also it is a dynamic endocrine organ secreting multiple bioactive proteins - or adipocytokines - promoting inflammation and affecting glucose metabolism and vascular endothelial biology $[6,7]$.

Adipokines are big family secreted by white adipose tissue which is mainly located around internal organs and subcutaneous fat tissue. Not only adipocytes but also other cells present in the adipose tissue, mainly macrophages, contribute to the secretion of adipokines [7]. Secretion of these peptides elevates with increasing adiposity. Some of these peptides act as proinflammatory molecules, and some of them called as good adipokines and have the antiinflammatory role. Proinflammatory adipokines may drive insulin resistance, disturbance of glucose and lipid metabolism, vascular dysfunction, and immune cell tissue infiltration and activation. Although this role is more clearly shown in metabolic syndrome, obesity or diabetes they also role on psoriasis by contribution to the inflammation in skin and skin cell dysfunction $[7,8,9,10]$.

Apelin is a newly identified adipokine with peptide origin was first described by Tatemoto et al. [11] in 1998 with a widespread distribution over such variety of tissues such as kidney, heart, lung, adipose tissue, liver, endothelium, and human plasma. It mainly role in the regulation of cardiovascular and gastrointestinal system such as regulation of angiogenesis and endothelial and smooth muscle cell apoptosis, immune functions, as well as in bone physiology, fluid homeostasis and cardiovascular system embryonal development [12]. It has also been shown to enhance the sensitivity of cells to insulin and delay the development of metabolic disorders associated with obesity, to a large extent strong positive inotropic, hypotensive effect and cardioprotective effects [13]. The role of apelin is well defined in cardiopulmonary disorders and apelin pathway targeted therapies were considered as a new therapeutic approach in CVD $[13,14]$. The role of apelin is not well known in dermatologic diseases.

Apelin has a key regulator role on glucose and lipid metabolism and may be associated with insulin resistance, and similarly psoriasis is known to be associated with increased insulin resistance and other metabolic disorders such as dyslipidemia, hypertension, endothelial dysfunction and reduced vascular compliance and atherosclerosis; in this study we aimed to investigate if there is a significant difference in serum apelin levels between psoriasis patients and healthy controls.

\section{Materials and Methods}

\section{Patients and Healthy Subjects}

A prospective case-control study was conducted on 37 consecutive patients (23 males and 14 females) with psoriasis vulgaris and 40 healthy controls (17 male, 23 female). The study was conducted in the light of the declaration of Helsinki and followed a protocol approved by our institutional localboard (Ethical approval 2015/0048). Patients were recruited in the study after being given informed consent. Patients who have moderate to severe plaquetype psoriasis were included the study. Psoriatic patients who have diabetes, metabolic syndrome or obesity were not included in this study. Healthy adults, with no known diagnosis of cancer, CVD, diabetes mellitus, renal failure and hematologic disorders were included in the control group. The study was carried out in accordance with the World Medical Association Declaration of Helsinki and was approved by the Local Ethics Committee.

\section{Sample Collection}

Samples were collected from the patients and healthy volunteers. Each participant was present at the laboratory in the morning of sampling day, after fasting for 8-12 hours. Each participant was seated in an upright posture before venipuncture and throughout specimen collection. The tourniquet was taken off by the phlebotomist immediately to prevent hemolysis and hemoconcentration.

Venous blood was collected into serum separator tubes (BD Vacutainer; BectonDickinson, Meylan, France) with clot activator. Samples were centrifuged at 2000x g for $10 \mathrm{~min}$ with refrigerated bench top centrifuge and stored in $-80^{\circ} \mathrm{C}$ until analysis.

Biochemical analyses of total cholesterol, low density lipoprotein (LDL), high density lipoprotein (HDL), triglyceride (TG), glucose, hemoglobin A1c (HbA1c), C-reactive protein (CRP), and erythrocyte sedimentation rates (ESR) were done with AU 680, Beckman Coulter, USA. The methodology and intra/inter-assay analytical CV's were determined for two levels.

The serum apelin concentration was measured with the ELISA assay (Phoenix, Apelin12, California, USA).

\section{Statistical Analysis}

Statistical analyses were carried out using the "Statistical Package for the Social Sciences (SPSS) 15.0 for Windows (SPSS Inc., Chicago, IL, USA) software. Categorical variables were expressed as percentages and continuous variables as the mean \pm standard deviation (SD). The distribution of variables were assessed by Kolmogorov-Smirnov test. Differences between two groups were analyzed using "Student's t-test" (parametric distributed variables) and "Mann-Whitney U test" (nonparametric distrubuted variables) for continous variables and Pearson chi-square for categorical variables. 
For the analysis of correlation coefficients, Pearson and Spearmen correlation tests were used for normally and non-normally distributed variables, respectively.

\section{Results}

In total, the data of 77 patients were analyzed. The mean ages of participants were $43(S D \pm 12)$ and 41 (SD \pm 13$)$ years in patient and control group, respectively. Baseline characteristics of both groups were comparable and shown in Table 1.

There were not statistically significant differences between patient and control groups according to serum levels of total cholesterol, LDL, HDL, TG, glucose, HbA1c, CRP and ESR.

There were statistically significant differences between two groups according to serum apelin concentrations. The mean value of serum apelin concentration in control and patient groups were 0.13 and $0.10 \mathrm{ng} / \mathrm{mL}$, respectively $(\mathrm{p}<0.05)$. The box plots of serum apelin concentrations are shown in Figure 1.

The correlation between serum apelin concentrations and other parameters were evaluated. Serum apelin concentration was only correlated with age. The correlation between serum apelin concentration and age are shown in Figure 2. There was no correlation between serum apelin concentrations and other biochemical parameters, psoriasis area and severity index scores, and homeostatic model assessment-insulin resistance (HOMA-IR) values. Expectedly, there was association between serum total cholesterol level and ESR, HbA1C and HOMA-IR values. Serum TG concentration was correlated with $\mathrm{HbA1c}$ and HOMA-IR values. There was also the correlation between serum LDL concentration and HbA1c levels.

\section{Discussion}

Apelin is a newly defined adipokine with anti-inflammatory, antiatherogenic and cardioprotective effects [15]. It is a hypoxia inducible peptide, produced and secreted by adipocytes, stromal vascular structure, and cardiovascular tissues [16]. In addition to hypoxia, secretion of this peptide is controlled by different factors including tumor necrosis factor (TNF)-alpha and insulin $[16,17]$. The link between apelin and insulin was studied in different clinical studies, and challenging results have been reported in the literature. Some authors claim that when compared to normal

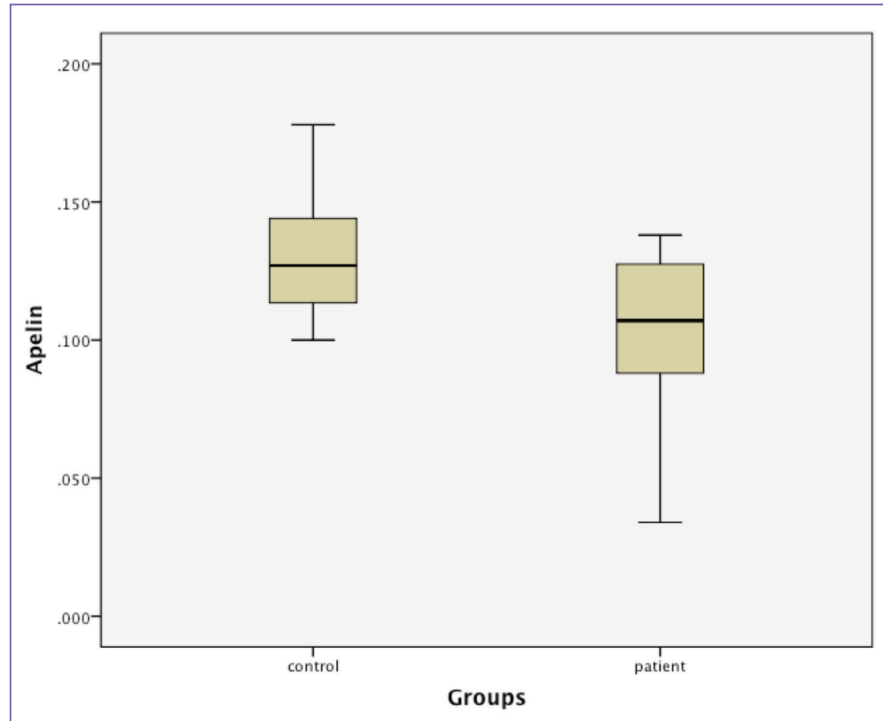

Figure 1. The boxplots of serum apelin concentrations according to the groups $(p<0.001)$

Table 1. Baseline characteristics of both groups

\begin{tabular}{|c|c|c|c|}
\hline & Patients $(n=37)$ & Control $(n=40)$ & $p$ value \\
\hline Age & $43 \pm 12$ & $41 \pm 13$ & $<0.001 \&$,\# \\
\hline Triglycerides & $158 \pm 136$ & $162 \pm 91$ & $0.334^{*}$ \\
\hline HDL cholesterol & $51 \pm 16$ & $50 \pm 14$ & $0.3^{*}$ \\
\hline Sedimentation & $20.7 \pm 16$ & $20.6 \pm 18.1$ & $0.976^{*}$ \\
\hline CRP & $0.7 \pm 0.8$ & $1.02 \pm 1.7$ & $0.796^{*}$ \\
\hline HOMA-IR & $2.35 \pm 7.73$ & $2.05 \pm 4.61$ & 0.879 \\
\hline $\mathrm{HbA1c}$ & $5.3 \pm 1.8$ & $5.9 \pm 0.7$ & $0.053^{*}$ \\
\hline \multicolumn{4}{|c|}{$\begin{array}{l}\text { F: Female, M: Male, LDL: Low density lipoprotein, HDL: High density lipoprotein, CRP: C-reactive protein, HbA1c: Hemoglobin A1c, HOMA-IR: Homeostatic model assessment- } \\
\text { insulin resistance. } \\
\text { Data are expressed as mean } \pm \text { standard deviation or as number of patients. } \\
\text { *p value is based on Mann-Whitney U test: } \$ \text { p value is based on chi-square test; \#p value is based on Student's t-test } \&_{p}<0.05 \text { compared to control group }\end{array}$} \\
\hline
\end{tabular}




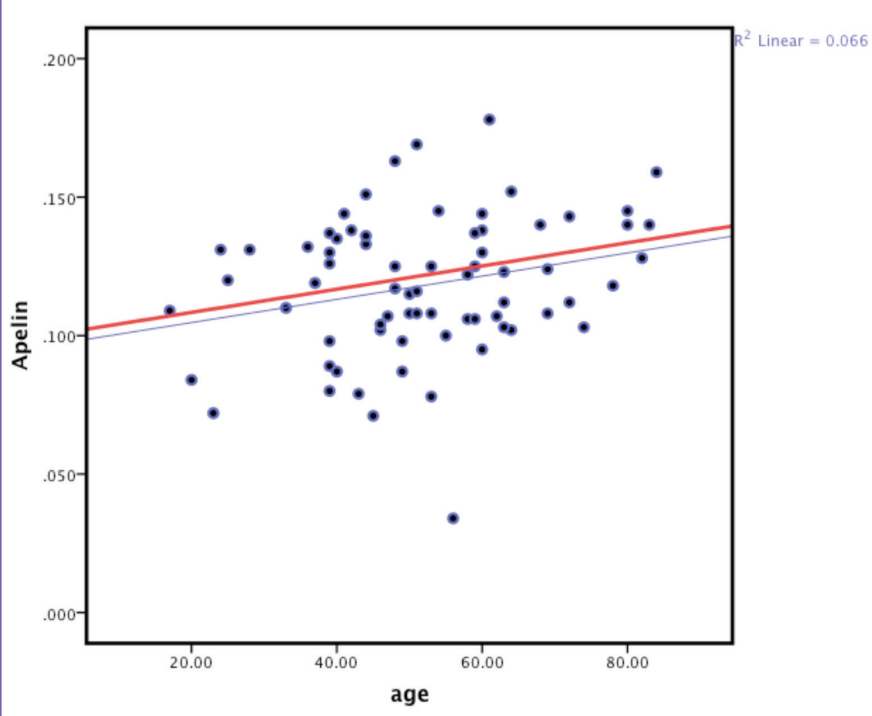

Figure 2. Correlation analysis of serum apelin concentration and age $(p=0.031)$

controls, plasma apelin concentration was reported to be increased in insulin resistant subjects, as well as in morbid obese individuals with type 2 diabetes mellitus and metabolic syndrome while in some studies lower concentrations of apelin was detected in obese patients $[18,19,20,21,22]$. The role of obesity in apelin secretion was reported to be mainly associated with increased hypoxia in adipose tissue. In our study, we did not include obese individuals or patients with metabolic syndrome for not to affect the apelin levels independently.

Decreased levels of apelin have been reported mainly in cardiovascular disorders, preeclamptic women and in polycystic ovary syndrome and were considered as novel biomarker for cardiovascular disorders [23,24,25,26]. Positive inotropic, antiatherogenic and cardioprotective effects have also been emphasized in these studies.

The role of apelin in skin disorders has been reported in few studies in the literature $[27,28,29]$. Dertlioglu et al. [27] reported increased levels of apelin in psoriasis patients, but they did not exclude patients with metabolic syndrome in their study. Also incerased levels of apelin have been reported in systemic scleroderma patients with conflicting results $[28,29]$. Kovacs et al. [30] investigated the expression of the major adipokines in sebaceoud glands of healthy skin samples and they did not detect apelin expression in sebocytes. As mentioned above adipose tissue produces both pro- and anti-inflammatory mediators that influence local and systemic inflammation and expressions of these peptides may change according to the underlying metabolic situation. Major adipokines such as adiponectin, leptin, resistin and visfatin that are known to be dysregulated in obesity and obesity-induced chronic inflammation. They were also found to be abnormal in psoriasis. However, in some studies, controversial data shows that the alterations of adipokine levels are similar to changes found in obesity but independently associated with psoriasis. Adiponectin, C1q/TNF-related proteins (CTRPs), omentin, and secreted frizzledrelated protein 5 (SFRP5) are anti-inflammatory adipokines produced by adipose tissue and their low levels have been shown in psoriatic patients in several studies [31]. Also, increased levels of proinflammatory adipokines such as leptin, chemerin and resistin have also been reported in psoriasis patients in different studies $[31,32,33]$.

\section{Study Limitation}

The small sample size is the main limitation of our study.

\section{Conclusion}

In our study, we detected decreased levels of apelin which has an anti-inflammatory role in psoriasis patients when compared to healthy controls. According to these results, we believe that in psoriasis patients chronic inflammation of psoriasis may also lead dysregulation of adipokines independently from obesity. We also think that decreased levels of apelin seem be related to chronic inflammation of psoriasis that induces hypoxia leading to adipose tissue dysfunction and adipose tissue fibrosis and may result in decreased release of anti-inflammatory adipokines. Decreased levels of apelin in psoriasis patients may be associated with this mechanism of adipose tissue dysfunction and adipose tissue fibrosis that result in decreased release of apelin. To prove this further effect studies with the larger population are needed.

\section{Ethics}

Ethics Committee Approval: The study was conducted in the light of the declaration of Helsinki and followed a protocol approved by our institutional localboard (Ethical approval 2015/0048).

Informed Consent: Patients were recruited in the study after being given informed consent.

Peer-review: Internally peer-reviewed.

\section{Authorship Contributions}

Surgical and Medical Practices: T.K.Ü.U., H.E., A.S.K., N.A., Concept: T.K.Ü.U., H.E., Design: T.K.Ü.U., H.E., Data Collection or Processing: T.K.Ü.U., H.E., Analysis or Interpretation: T.K.Ü.U., H.E., N.A., Literature Search: T.K.Ü.U., A.S.K., Writing: T.K.Ü.U., A.S.K.

Conflict of Interest: No conflict of interest was declared by the authors.

Financial Disclosure: The authors declared that this study received no financial support. 


\section{References}

1. Radtke MA, Schäfer I, Glaeske G, Jacobi A, Augustin M. Prevalence and comorbidities in adults with psoriasis compared to atopic eczema. J Eur Acad Dermatol Venereol 2017;31:151-157.

2. Gerdes S, Mrowietz U, Boehncke WH. Comorbidity in psoriasis. Hautarzt 2016;67:438-444.

3. Gulliver W. Long-term prognosis in patients with psoriasis. $\mathrm{Br} J$ Dermatol 2008:159:2-9.

4. Malkic Salihbegovic E, Hadzigrahic N, Cickusic AJ. Psoriasis and metabolic syndrome. Med Arch 2015;69:85-87.

5. Mehta NN, Azfar RS, Shin DB, Neimann AL, Troxel AB, Gelfand JM. Patients with severe psoriasis are at increased risk of cardiovascular mortality: cohort study using the General Practice Research Database. Eur Heart J 2010;31:1000-1006.

6. Sterry W, Strober BE, Menter A. International Psoriasis Council. Obesity in psoriasis:the metabolic, clinical and therapeutic implications. Report of an interdisciplinary conference and review. Br J Dermatol 2007;157:649-655.

7. Wolk K, Sabat R. Adipokines in psoriasis: An important link between skin inflammation and metabolic alterations. Rev Endocr Metab Disord 2016;17:305-317.

8. Skoczylas A, Piecha G, Więcek A. Effects of antihypertensive treatment on plasma apelin, resistin, and visfatin concentrations. Pol Arch Med Wewn 2016;126:243-253.

9. Coban M, Tasli L, Turgut S, Özkan S, Tunç Ata M, Akın F. Association of Adipokines, Insulin Resistance, Hypertension and Dyslipidemia in Patients with Psoriasis Vulgaris. Ann Dermatol 2016;28:74-79.

10. Gerdes S, Rostami-Yazdi M, Mrowietz U. Adipokines and psoriasis. Exp Dermatol 2011;20:81-87.

11. Tatemoto K, Hosoya M, Habata Y, R Fujii, T Kakegawa, Zou MX, Kawamata Y, Fukusumi S, Hinuma S, Kitada C, Kurokawa T, Onda H, Fujino M. Isolation and characterization of a novel endogenous peptide ligand for the human APJ receptor. Biochem Biophys Res Commun 1998;251:471-476.

12. Ladeiras-Lopes R, Ferreira-Martins J, Leite-Moreira AF. The apelinergic system:the role played in human physiology and pathology and potentialtherapeutic applications. Arq Bras Cardiol 2008;90:343-349.

13. Kazemi-Bajestani SM, Patel VB, Wang W, Oudit GY. Targeting the ACE2 and Apelin Pathways Are Novel Therapies for Heart Failure: Opportunities and Challenges. Cardiol Res Pract 2012;2012:823193.

14. Zhong JC, Zhang ZZ, Wang W, McKinnie SMK, Vederas JC, Oudit GY. Targeting the apelin pathway as a novel therapeutic approach for cardiovascular diseases. Biochim Biophys Acta 2017;1863:1942-1950.

15. Boucher J, Masri B, Daviaud D, Gesta S, Guigne C, Mazzucotelli A, CastanLaurell I, Tack I, Knibiehler B, Carpene C, Audigier Y, Saulnier-Blache JS, Valet P. Apelin, a newly identified adipokine up-regulated by insulin and obesity. Endocrinology 2005;146:1764-1771.

16. Geiger K, Muendlein A, Stark N, Saely CH, Wabitsch M, Fraunberger P, Drexel $\mathrm{H}$. Hypoxia induces apelin expression in human adipocytes. Horm Metab Res 2011;43:380-385.
17. Daviaud D, Boucher J, Gesta S, Dray C, Guigne C, Quilliot D, Ayav A, Ziegler O, Carpene C, Saulnier-Blache JS, Valet P, Castan-Laurell I. TNFalpha upregulates apelin expression in human and mouse adipose tissue. FASEB J 2006;20:1528-1530.

18. Xu S, Tsao PS, Yue P. Apelin and insulin resistance: another arrow for the quiver? J Diabetes 2011;3:225-231.

19. Karbek B, Bozkurt NC, Topaloglu O, Aslan MS, Gungunes A, Cakal E, Delibasi T. Relationship of vaspin and apelin levels with insulin resistance and atherosclerosis in metabolic syndrome. Minerva Endocrinol 2014;39:99-105.

20. Erdem G, Dogru T, Tasci I, Sonmez A, Tapan S. Low plasma apelin levels in newly diagnosed Type 2 Diabetes Mellitus. Exp Clin Endocrinol Diabetes 2008; 116:289-292.

21. Tasci I, Dogru T, Naharci I, Erdem G, Yilmaz MI, Sonmez A, Bingol N, Kilic $\mathrm{S}$, Bingol S, Erikci S. Plasma apelin is lower in patients with elevated LDLcholesterol. Exp Clin Endocrinol Diabetes 2007;115:428-432.

22. Tapan S, Tascilar E, Abaci A, Sonmez A, Kilic S, Erbil MK, Ozcan O. Decreased plasma apelin levels in pubertal obese children. J Pediatr Endocrinol Metab 2010;23:1039-1046.

23. Ellinor PT, Low AF, Macrae CA. Reduced apelin levels in lone atrial fibrillation. Eur Heart J 2006;27:222-226.

24. Bortoff KD, Qiu C, Runyon S, Williams MA, Maitra R. Decreased maternal plasma apelin concentrations in preeclampsia. Hypertens Pregnancy 2012;31:398-404.

25. Kim J, Kang Y, Kojima Y, Lighthouse JK, Hu X, Aldred MA, McLean DL, Park $H$, Comhair SA, Greif DM, Erzurum SC, Chun HJ. An endothelial apelinFGF link mediated by miR-424 and miR-503 is disrupted in pulmonary arterialhypertension. Nat Med 2013;19:74-82.

26. Altinkaya SÖ, Nergiz S, Küçük M, Yüksel H. Apelin levels in relation with hormonal and metabolic profile in patients with polycystic ovary syndrome. Eur J Obstet Gynecol Reprod Biol 2014;176:168-172.

27. Dertlioglu SB, Cicek D, Suleyman A. Increased serum apelin-12 and lipid profile in patients with and without psoriasis. Eur J Dermatol 2013;23:885886.

28. Żółkiewicz J, Stochmal A, Rudnicka L. The role of adipokines in systemic sclerosis: a missing link? Arch Dermatol Res 2019;311:251-263.

29. Aozasa N, Asano Y, Akamata K, Noda S, Masui Y, Yamada D, Tamaki Z, Tada $\mathrm{Y}$, Sugaya M, Kadono T, Sato S. Serum apelin levels: clinical association with vascular involvements in patients with systemic sclerosis. J Eur Acad Dermatol Venereol 2013;27:37-42.

30. Kovács D, Lovászi M, Póliska S, Oláh A, Bíró T, Veres I, Zouboulis CC, Ståhle M, Rühl R, Remenyik E, Törőcsik D. Sebocytes differentially express and secrete adipokines. Exp Dermatol 2016;25:194-199.

31. Mancuso P. The role of adipokines in chronic inflammation. Immunotargets Ther 2016;5:47-56.

32. Gerdes S, Rostami-Yazdi M, Mrowietz U. Adipokines and psoriasis. Exp Dermatol 2011;20:81-87.

33. Coimbra S, Catarino C, Santos-Silva A. The triad psoriasis-obesity-adipokine profile. J Eur Acad Dermatol Venereol 2016;30:1876-1885. 